\title{
The influence of a model subglacial lake on ice dynamics and internal layering
}

\author{
Eythor Gudlaugsson $^{1}$, Angelika Humbert ${ }^{2,3}$, Thomas Kleiner $^{2}$, Jack Kohler ${ }^{4}$, and Karin Andreassen ${ }^{1}$ \\ ${ }^{1}$ Centre for Arctic Gas Hydrate, Environment and Climate (CAGE), Department of Geology, UiT - The Arctic University of \\ Norway, Troms $\varnothing$, Norway \\ ${ }^{2}$ Section of Glaciology, Alfred Wegener Institute Helmholtz Center for Polar and Marine Research, Bremerhaven, Germany \\ ${ }^{3}$ Department of Geosciences, University of Bremen, Bremen, Germany \\ ${ }^{4}$ Norwegian Polar Institute, Fram Centre, Troms $\varnothing$, Norway \\ Correspondence to: Eythor Gudlaugsson (eythor.gudlaugsson@uit.no)
}

Received: 27 June 2015 - Published in The Cryosphere Discuss.: 28 July 2015

Revised: 18 January 2016 - Accepted: 13 March 2016 - Published: 5 April 2016

\begin{abstract}
As ice flows over a subglacial lake, the drop in bed resistance leads to an increase in ice velocities and a draw down of isochrones and cold ice. The ice surface flattens as it adjusts to the lack of resisting forces at the base. The rapid transition in velocity induces changes in ice viscosity and releases deformation energy that can raise the temperature locally. Recent studies of Antarctic subglacial lakes indicate that many lakes experience very fast and possibly episodic drainage, during which the lake size is rapidly reduced as water flows out. Questions that arise are what effect this would have on internal layers within the ice and whether such past drainage events could be inferred from isochrone structures downstream.

Here, we study the effect of a subglacial lake on ice dynamics as well as the influence that such short timescale drainage would have on the internal layers of the ice. To this end, we use a full Stokes, polythermal ice flow model. An enthalpy-gradient method is used to account for the evolution of temperature and water content within the ice.

We find that a rapid transition between slow-moving ice outside the lake, and full sliding over the lake, can release considerable amounts of deformational energy, with the potential to form a temperate layer at depth in the transition zone. In addition, we provide an explanation for a characteristic surface feature commonly seen at the edges of subglacial lakes, a hummocky surface depression in the transition zone between little to full sliding. We also conclude that rapid changes in the horizontal extent of subglacial lakes and slippery patches, compared to the average ice column veloc-
\end{abstract}

ity, can create a traveling wave at depth within the isochrone structure that transfers downstream with the advection of ice, thus indicating the possibility of detecting past drainage events with ice penetrating radar.

\section{Introduction}

Nearly 400 subglacial lakes have been identified in Antarctica based on radar data and satellite measurements (Wright and Siegert, 2012), as well as at least two subglacial lakes in Greenland, all of which satisfy established criteria for identification of subglacial lakes (Palmer et al., 2013). Subglacial lakes are typically located either in the ice-sheet interior, close to ice divides where surface slopes are low and ice is thick, or in areas of higher ice velocity where internal ice deformation and sliding add to geothermal energy to produce melting at the base (Siegert et al., 1996; Dowdeswell and Siegert, 1999).

Subglacial lakes have been hypothesized to play a role in the initiation of fast flow by (1) providing a steady stream of water downstream of their location, lubricating the base (Gray et al., 2005; Langley et al., 2014); (2) substantially influencing the thermal regime of the ice, gradually warming the basal ice from below; or (3) providing ice with enough thermal momentum to resist freezing on downstream of the lake (Bell et al., 2007). 
The reason why so few lakes have been discovered in Greenland, despite considerable efforts and relatively dense surveying compared to Antarctica, is believed to be because of the generally warmer ice and higher surface slopes in Greenland, which favor rapid and more efficient drainage as well as increased vulnerability to drainage instabilities (Pattyn, 2008). In addition, the large supply of surface meltwater to the base of the Greenland Ice Sheet through hydrofracturing means that the drainage networks in place are probably already highly efficient and, thus, capable of draining subglacial water effectively and preventing or limiting subglacial lake development (Palmer et al., 2013).

Apart from Lake Vostok, the largest subglacial lake in the world, as well as a few other ones, the typical subglacial lake is around $10 \mathrm{~km}$ in diameter (Siegert, 2000). Recent studies have presented compelling evidence of rapid transport of water stored in subglacial lakes, indicating that lakes can either drain episodically or transiently on relatively short timescales (Gray et al., 2005; Wingham et al., 2006; Fricker et al., 2007). Lakes appear to form a part of a connected hydrological network, with upstream lakes draining into downstream ones as subglacial water moves down the hydrological potential (Siegert et al., 2007). Both ice and water transport a substantial amount of sediment over time which is deposited in the lakes, thus reducing their size over long timescales. Sedimentation rates can vary from close to 0 to several millimeters per year, with sediment layers estimated to be up to several hundreds of meters thick in some lakes (Christoffersen et al., 2008; Bentley et al., 2013). The dominant mechanism in transporting sediment to subglacial lakes is thought to be influx of sediment-laden water for open-system, or active, lakes, and melt-out from the overlying ice for closed-system lakes, where water exchange happens purely through melting and freezing (Bentley et al., 2013). Subglacial lakes thus change size on a variety of timescales with different mechanisms, from fast drainage to slow sedimentation.

The presence of a subglacial lake is often signalled by a flattening of the ice surface, given that the lake is in hydrostatic equilibrium, and as a local speed-up of ice velocities. This draws down cold ice and deflects isochrone layers within the ice (Weertman, 1976).

Numerous studies have investigated the effect of spatially varying basal (or surface) conditions on ice dynamics and the internal layering of ice, such as melting or basal resistance. Previously, Leysinger Vieli et al. (2007) studied the effect of areas with basal sliding or melting on internal layer architecture, but not explicitly a subglacial lake. The effect of a subglacial lake on ice dynamics was investigated by Sergienko et al. (2007), who used a 2-D vertically integrated flow equation to study ice-sheet response to transient changes in lake geometry and basal resistance, and by Pattyn (2008) who investigated the stability of a subglacial lake to drainage events. The interaction between lake circulation and ice dynamics and its effect on the basal mass balance have also been studied by Thoma et al. (2010).
The aim of this study is to investigate the influence of a subglacial lake on ice dynamics and the effect it has on the isochrone structure within the ice. As all stress components are important for such an interaction, we use a fully 3-D thermomechanically coupled full Stokes ice-sheet model, implemented in the commercial finite element software COMSOL. We employ an enthalpy-gradient method to account for the softening effect of ice temperature and water content on ice viscosity (Aschwanden et al., 2012) and we show how temporally varying basal conditions can lead to the appearance of flow bands, or arches and troughs, within the internal layering downstream of the original flow disturbance.

\section{Model description}

\subsection{Ice flow}

Ice is treated as an incompressible fluid with constant density, obeying conservation laws for mass and momentum:

$\nabla \cdot \boldsymbol{u}=0$

and

$\nabla \cdot \sigma=-\rho g$

where $\boldsymbol{u}$ is the velocity vector, $\boldsymbol{g}$ the gravitational acceleration, $\rho$ the ice density, and $\sigma$ the Cauchy stress tensor. The Cauchy stress tensor is given by

$\boldsymbol{\sigma}=\boldsymbol{\tau}-p \mathbf{I}$,

where $\boldsymbol{\tau}$ and $p \mathbf{I}$ are the deviatoric and the isotropic parts, $p$ is pressure, and $\mathbf{I}$ is the identity matrix. Inertial forces are assumed negligible and only body forces arising from gravity are taken into account.

Ice is assumed to follow Glen's flow law (Steinemann, 1954; Glen, 1955), in which deviatoric stresses are related to strain rates $(\dot{\boldsymbol{\varepsilon}})$ by

$\boldsymbol{\tau}=2 \eta \dot{\boldsymbol{\varepsilon}}$

and

$\eta\left(T^{\prime}, W, \dot{\varepsilon}_{\mathrm{e}}\right)=\frac{1}{2}\left[A_{t}\left(T^{\prime}, W\right)\right]^{-\frac{1}{n}} \dot{\varepsilon}_{\mathrm{e}}^{\frac{1-n}{n}}$,

where $\eta$ is the effective viscosity, $\dot{\varepsilon}_{\mathrm{e}}$ is the effective strain rate, $\left(A_{t}\right)$ is a rate factor that depends on the homologous temperature $\left(T^{\prime}\right)$ and the water content of the ice $(W)$, and $n$ is the power-law exponent in Glen's flow law. The homologous temperature $T^{\prime}=T+\gamma p$ corrects for the dependence of the pressure-melting point $\left(T_{\mathrm{m}}\right)$ on pressure, where $\gamma$ is the Clausius-Clapeyron constant. The formulation of the rate factor follows (Duval, 1977) 
$A_{t}(T, p, W)=A(T, p) \times(1+1.8125 W[\%])$,

where

$A(T, p)=A\left(T^{\prime}\right)=A_{0} e^{-Q / R T^{\prime}}$,

and $A_{0}$ is a pre-exponential constant, $Q$ is the activation energy, and $R$ is the universal gas constant, with numerical values listed in Table 1 (Greve and Blatter, 2009).

\subsection{Enthalpy balance}

An enthalpy-gradient method (Aschwanden et al., 2012) is employed, as opposed to the typically used cold-ice formulation, which is incapable of reproducing correctly the rheology of temperate layers within ice sheets. The enthalpy formulation allows for the possibility of including liquid water content within temperate ice, based on mixture theory, without explicitly tracking the cold/temperate transition surface (Aschwanden et al., 2012; Greve, 1997). In the enthalpygradient method, enthalpy replaces temperature as the thermodynamical state variable, such that

$$
\begin{aligned}
& \rho\left(\frac{\partial H}{\partial t}+\boldsymbol{u} \cdot \nabla H\right) \\
& \quad=\nabla \cdot\left(\left\{\begin{array}{cc}
K_{\mathrm{i}}(H) \nabla H & \text { if } H<H_{T_{\mathrm{m}}}(p) \\
k(H, p) \nabla T_{\mathrm{m}}(p)+K_{0} \nabla H & \text { if } H \geq H_{T_{\mathrm{m}}}(p)
\end{array}\right\}\right)+Q,
\end{aligned}
$$

where $H=H(T, W, p)$ is the temperature and watercontent-dependent specific enthalpy and $Q=4 \eta \dot{\varepsilon}_{\mathrm{e}}^{2}$ is the heat dissipation due to internal deformation. The conduction term in Eq. (8) depends on whether the ice is cold $\left(H<H_{T_{\mathrm{m}}}(p)\right)$ or temperate $\left(H \geq H_{T_{\mathrm{m}}}(p)\right)$. The conduction coefficient for cold is ice defined as $K_{\mathrm{i}}=k / c$, where $k$ is the thermal conductivity and $c$ is the heat capacity, both assumed to be constant (Table 1). $H_{T_{\mathrm{m}}}(p)$ is the specific enthalpy of the pressure-dependent melting point of ice. The diffusivity for temperate ice is poorly constrained as little is known about the transport of microscopic water within temperate ice (Aschwanden et al., 2012; Hutter, 1982). In practice, we use the value $K_{0}=10^{-3} K_{\mathrm{i}}$, shown by Kleiner et al. (2015) to be sufficiently low to suppress transport of water by diffusion through the ice matrix, while still numerically stable.

\subsection{Age equation}

In addition to the balance equations above, we solve a separate equation for the ice age $(\chi)$ to determine the influence of the lake on the isochrone structure (Hindmarsh et al., 2009; Parrenin et al., 2006; Parrenin and Hindmarsh, 2007; Leysinger Vieli et al., 2007):

$$
\frac{\partial \chi}{\partial t}+\boldsymbol{u} \cdot \nabla \chi=1+\left(d_{\chi} \nabla^{2} \chi\right)
$$

where $\chi$ is the age of ice and the second term on the right represents a diffusivity term needed for numerical stability, in which $d_{\chi}$ is the numerical diffusivity.
Table 1. Values for constants used in the study.

\begin{tabular}{lll}
\hline & Constants & Values \\
\hline$\alpha$ & bed inclination & $0.3,0.1^{\circ}$ \\
$\rho$ & density of ice & $910 \mathrm{~kg} \mathrm{~m}^{-3}$ \\
$g$ & gravitational acceleration & $9.81 \mathrm{~m} \mathrm{~s}^{-2}$ \\
$n$ & flow law exponent & 3,1 \\
$\gamma$ & Clausius-Clapeyron constant & $9.8 \times 10^{-8} \mathrm{~K} \mathrm{~Pa}^{-1}$ \\
$T_{\mathrm{m}}^{0}$ & melting point at atm. pressure & $273.15 \mathrm{~K}$ \\
$A_{0}$ & pre-exp. constant $(T \leq 263.15 \mathrm{~K})$ & $3.985 \times 10^{-13} \mathrm{~s}^{-1} \mathrm{~Pa}^{-3}$ \\
& $-\quad(T>263.15 \mathrm{~K})$ & $1.916 \times 10^{-3} \mathrm{~s}^{-1} \mathrm{~Pa}^{-3}$ \\
$Q$ & activation energy $(T \leq 263.15 \mathrm{~K})$ & $60 \mathrm{~kJ} \mathrm{~mol}^{-1}$ \\
& $-\quad \quad(T>263.15 \mathrm{~K})$ & $139 \mathrm{~kJ} \mathrm{~mol}^{-1}$ \\
$R$ & universal gas constant & $8.3145 \mathrm{~J} \mathrm{~mol} \mathrm{~K})^{-1}$ \\
$k$ & thermal conductivity & $2.1 \mathrm{~W}\left(\mathrm{~m} \mathrm{~K}^{-1}\right.$ \\
$c$ & heat capacity & $2009 \mathrm{~J}\left(\mathrm{~kg} \mathrm{~K}^{-1}\right.$ \\
$L$ & latent heat of fusion & $3.35 \times 10^{5} \mathrm{~J} \mathrm{~kg}^{-1}$ \\
$d_{\chi}$ & diffusion coefficient & $10^{-13} \mathrm{~m}^{2} \mathrm{~s}^{-1}$ \\
$C$ & friction coefficient & $10^{13}, 10^{10}\left(\mathrm{~s} \mathrm{~m}^{2}\right) \mathrm{kg}^{-1}$ \\
$h$ & ice thickness & $1500,3000 \mathrm{~m}$ \\
$a_{\mathrm{S}}$ & surface accumulation & $0 \mathrm{~m} \mathrm{~s}^{-1}$ \\
$T_{\mathrm{S}}$ & surface temperature & $-30^{\circ} \mathrm{C}$ \\
$q_{\text {geo }}$ & geothermal flux & $55 \mathrm{~mW} \mathrm{~m}^{-2}$ \\
$\eta_{\text {const }}$ & ice viscosity (constant $)$ & $10^{14} \mathrm{~Pa} \mathrm{~s}^{-1}$ \\
\hline
\end{tabular}

\subsection{Boundary conditions (BCs)}

At the surface, stresses arising from atmospheric pressure and wind can be neglected as they are very small compared to the typical stresses in the ice sheet (Greve and Blatter, 2009), resulting in a traction-free $\mathrm{BC}$ :

$\boldsymbol{\sigma} \cdot \boldsymbol{n}=0$,

where $\boldsymbol{n}$ is the normal vector pointing away from the ice. Accumulation and ablation $\left(a_{\mathrm{s}}\right)$ at the surface are assumed to be 0 , giving the kinematic surface $\mathrm{BC}$ as

$\frac{\partial z_{\mathrm{s}}}{\partial t}+u \frac{\partial z_{\mathrm{s}}}{\partial x}+v \frac{\partial z_{\mathrm{s}}}{\partial y}-w=a_{\mathrm{s}}=0$,

where $z_{\mathrm{s}}$ is the surface elevation. We employ an inverse Weertman-type sliding law (Eq. 12), where the basal drag $\left(\boldsymbol{\tau}_{\mathrm{b}}\right)$ is expressed as a function of the velocity of the ice $\left(\boldsymbol{u}_{\mathrm{b}}\right)$ immediately above the ice/base interface, except over the lake surface where basal traction is set to 0 (full slip). With basal sliding exponents $(p, q)=(1,0)$ appropriate for ice-streaming conditions, the sliding relationship simplifies to a linear relationship between basal sliding and basal traction. The ice is assumed to be in hydrostatic equilibrium everywhere and the basal normal pressure $\left(\tau_{\mathrm{n}}\right)$ taken as the ice overburden pressure. Ice accretion and melt at the base are assumed to be 0 and along with the stress $\mathrm{BC}$ at the surface, a no-penetration condition is used to close the system: 
$\boldsymbol{u}_{\mathrm{b}}=-C^{-1} \frac{\left|\tau_{\mathrm{b}}\right|^{p-1} \boldsymbol{\tau}_{\mathrm{b}}}{\tau_{\mathrm{n}}^{q}}=-C^{-1} \boldsymbol{\tau}_{\mathrm{b}} \Rightarrow \boldsymbol{\tau}_{\mathrm{b}}=C \boldsymbol{u}_{\mathrm{b}}$,

and

$\boldsymbol{u} \cdot \boldsymbol{n}=0$

where $C$ is the sliding coefficient (Table 1). Periodic BCs for the inlet/outlet are used, such that the velocity, pressure, and specific enthalpy are the same at the upstream and downstream extremes. On the side boundaries of the domain, symmetry for velocity and thermal insulation is imposed:

$\boldsymbol{u}_{\text {in }}=\boldsymbol{u}_{\text {out }} \quad p_{\text {in }}=p_{\text {out }} \quad H_{\text {in }}=H_{\text {out }}$,

$$
\boldsymbol{K}=\left[\mu\left(\nabla \boldsymbol{u}+(\nabla \boldsymbol{u})^{T}\right)\right] \boldsymbol{n}, \quad \boldsymbol{K}-(\boldsymbol{K} \cdot \boldsymbol{n}) \boldsymbol{n}=0,
$$$$
\boldsymbol{u} \cdot \boldsymbol{n}=0
$$

$-\boldsymbol{n} \cdot \nabla H=0$.

At the surface, a value is set for specific enthalpy $\left(H_{\mathrm{S}}\right)$ corresponding to a surface temperature of $T_{\mathrm{S}}=-30^{\circ} \mathrm{C}\left(W_{\mathrm{s}}=0\right.$, $p_{\mathrm{s}}=0$ ) such that

$H_{\mathrm{s}}=H_{\mathrm{i}}+c\left(T_{\mathrm{s}}-T_{\mathrm{m}}\right)$.

At the base, the geothermal flux $\left(q_{\mathrm{geo}}\right)$ is used for cold ice and a zero flux for temperate ice:

$\boldsymbol{n} \cdot\left(\left\{\begin{array}{l}-K_{\mathrm{i}} \nabla H \\ -K_{0} \nabla H\end{array}\right\}\right)=\left\{\begin{array}{ll}q_{\mathrm{geo}}, & \text { if } T<T_{\mathrm{m}} \\ 0, & \text { if } T=T_{\mathrm{m}}\end{array}\right\}$,

where $H_{\mathrm{i}}$ is the specific enthalpy of pure ice at the melting temperature. To determine correctly the basal $\mathrm{BC}$ for the enthalpy field equation, switching between a Dirichlet and a Neumann condition is necessary (Aschwanden et al., 2012; Kleiner et al., 2015), depending on basal temperature, water availability at the base, and whether a temperate layer exists immediately above it. Here we opt for a simpler, more computationally efficient $\mathrm{BC}$ where the geothermal flux is gradually decreased in the specific enthalpy range corresponding to $\left[\left(T_{\mathrm{m}}-0.2^{\circ} \mathrm{C}\right)\left(T_{\mathrm{m}}\right)\right]$, with a smoothed Heaviside function with continuous derivatives.

For the age-depth relation (Eq. 9), periodic BCs are used for the inlet and outlet. At the surface, the age is set to $\chi_{\mathrm{s}}=0$. Zero normal fluxes are used for the side boundaries and the lower boundary.

$-\boldsymbol{n} \cdot(-\nabla \chi)=0$

\subsection{Computational domain}

We define the computational domain as a rectangular box $350 \mathrm{~km}$ long and $100 \mathrm{~km}$ wide with a fixed bed slope $(\alpha)$.
Table 2. Values for lake sizes used in the paper.

\begin{tabular}{lcr}
\hline Lake size & Major axis & Minor axis \\
\hline$L_{S}$ & $10 \mathrm{~km}$ & $5 \mathrm{~km}$ \\
$L_{M}$ & $20 \mathrm{~km}$ & $10 \mathrm{~km}$ \\
$L_{L}$ & $30 \mathrm{~km}$ & $15 \mathrm{~km}$ \\
\hline
\end{tabular}

Three different lakes sizes are used, based on typical sizes of subglacial lakes found in Antarctica (Siegert et al., 1996; Siegert and Kwok, 2000). The lakes are all elliptical in shape, with major and minor axes defined in Table 2. The major axis is aligned with the direction of flow. The model experiments are all either steady-state solutions or start from steady-state solutions.

Throughout the domain, extruded triangular (prismatic) elements are used with a horizontal resolution down to $\sim 500 \mathrm{~m}$ at the lake edges. This relatively high resolution is needed in order to capture the effect of strain softening of ice around the lake edges, where velocity gradients are large, and to resolve properly the upper surface. The model uses 15 vertical layers, which become thinner towards the base, where the thinnest layer has a thickness of $\sim 35 \mathrm{~m}$.

\section{Model experiments}

The aim of the study is to show how the presence of a subglacial lake affects ice dynamics and thermal resolution and to follow its effects on internal layering through simple temporally dependent and steady-state experiments.

All transient simulations are started from an initially steady-state configuration, where equations for mass, momentum, and enthalpy are solved jointly with a direct solver along with equations for surface or grid evolution. All presented results are based on simulations with a fully nonlinear ice viscosity $(n=3)$ unless otherwise stated explicitly, and all numerical values for model constants are defined in Table 1 .

The lake itself is modeled as a "slippery spot" (Pattyn et al., 2004; Sergienko et al., 2007). The lake surface is assumed to be fixed to the bed plane. In reality, any changes to lake size or volume would lead to vertical movement of the lake surface, which in itself would induce an expression at the surface of the ice. Sergienko et al. (2007) found that vertical movement of lake surfaces due to drainage resulted only in small changes to ice velocity and that the ice surface reached its initial stage after just a few years, indicating that it would not lead to a significant disturbance in isochrone structure compared to changes in the horizontal lake extent. Here we consider only planar changes in lake geometry or changes in lake size fixed to the bed plane.

Water draining from subglacial lakes is likely to have an impact on ice dynamics and isochrone structures downstream of the lake, either through melting of ice or changes in basal 

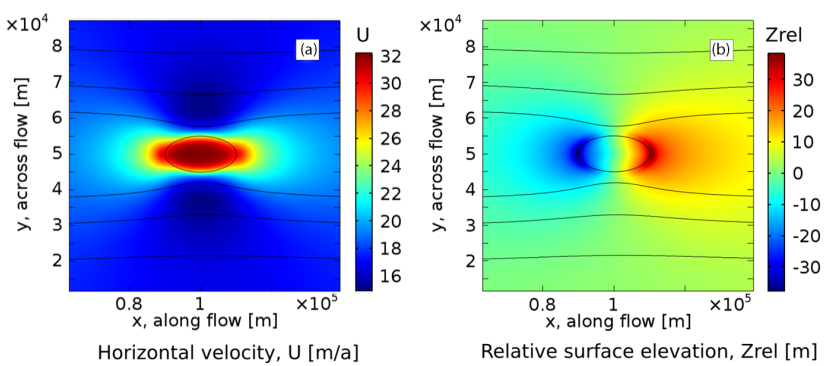

Figure 1. Two-dimensional surface plots of horizontal velocity (a) in $\mathrm{m} \mathrm{a}^{-1}$ and relative surface elevation (b) in meters. The outline of the lake ( $L_{M}$ lake size, $\left.n=3\right)$ and streamlines are shown in black and flow is from left to right.

water pressure and sliding, although no representation of subglacial hydrology is included here. The effect the draining water will have on isochrone layers will depend on the state of the drainage system and how the water is transported downstream (Stearns et al., 2008) but will likely be limited by the swiftness of the ice response compared to the time needed to perturb isochrone layers considerably.

The lack of basal friction over the lake results in increased velocities, not just over the lake but also a considerable distance both upstream and downstream of the lake that depends on ice thickness, basal traction (Hindmarsh, 2006; Kamb and Echelmeyer, 1986), and the size of the lake. This distance is around $15 \mathrm{~km}$ for the $L_{S}$ lake size, $50 \mathrm{~km}$ for $L_{M}$, and $100 \mathrm{~km}$ for the $L_{L}$ lake size, defined as the distance it takes for the horizontal velocity to drop below 1.05 times the background velocity. Figure 1a shows the surface velocity with black lines indicating streamlines and Fig. 1b shows the relative change in surface elevation caused by the presence of the lake, where the general slope has been subtracted from the surface. The surface responds to the change in basal conditions by becoming flatter and with more than a doubling of horizontal velocities over the lake. Streamlines contract and ice is brought in towards the lake from the sides.

Figure 2 shows different model output in vertical cross sections, through the center of the lake, in the direction of flow for the $L_{M}$ lake size. Over the lake, the ice basically moves as an ice shelf with more or less uniform horizontal velocity throughout the ice column (Fig. 2a). At the upstream end of the lake, a strong downward movement of ice causes cold ice from the upper layers to be drawn down towards the bottom, steepening the temperature gradient close to the base. Conversely, at the downstream end a strong upward flow restores internal layers to their prior depths (Fig. 2b).

The temperature and microscopic water content within the ice are shown in Fig. 2b. Black lines represent streamlines which coincide, or line up, with isochrone layers for steadystate simulations (Hindmarsh et al., 2006).

The intense internal deformation close to the borders of the lake, where ice velocities change significantly over short distances, gives rise to a thin temperate layer of ice both at
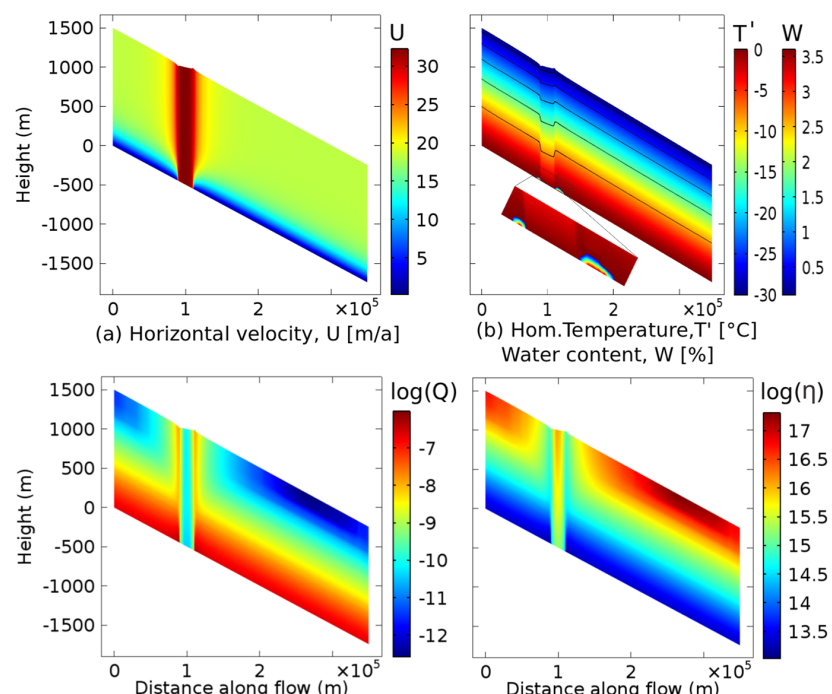

(c) log. of Internal deformation energy $\left[\mathrm{W} \mathrm{m}^{-3}\right]$

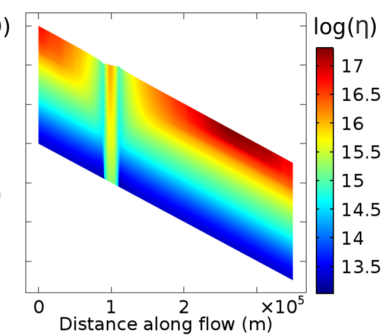

(d) log. of Ice viscosity [Pa s]

Figure 2. Along flow profiles, through the center of the lake $\left(L_{M}\right.$ lake size, $n=3$ ). (a) shows horizontal velocity in $\mathrm{m} \mathrm{a}^{-1}$. (b) shows the homologous temperature in ${ }^{\circ} \mathrm{C}$ and water content in percentage. The black lines represent streamlines. The inset figure shows a close-up of the temperate layers at the lake edges (same color scales). In (c) we see the logarithm of the internal deformation energy $\mathrm{W} \mathrm{m}^{-3}$ while (d) shows the logarithm of the viscosity [Pa s].

the upstream and downstream ends of the lake (Fig. 2b). The vertical resolution is somewhat limited in the model but simulations with higher resolution do indicate that a temperate layer should form for the given velocity field, although its thickness might be slightly overestimated. This is strongly affected by the chosen sliding law and sliding coefficients and should not be considered representative of subglacial lakes in general.

Figure $2 \mathrm{c}$ shows the internal deformation energy, with high values near the base where velocity gradients are high. Maximum values are reached near the edges of the lake, in the transition zone between low and full sliding. Increases in temperature, pressure, and water content, and larger effective stress, all have the effect of decreasing the viscosity, which is why the lowest viscosity values are obtained at the base of the ice sheet, in particular around the edges of the lake (Fig. 2d). Generally low viscosity is furthermore obtained throughout the ice column over the lake boundary, extending all the way up to the surface, effectively creating a vertical zone of softer ice.

Figure 3a shows profiles of horizontal surface velocity for the three different lake sizes considered. As expected, velocity peaks over the lake surfaces and two fringe peaks at the lake edges are discernible for the smallest lake size as well.

A characteristic surface dip feature is observed at the upstream end of many lakes in Antarctica, for instance the Recovery Lakes (Bell et al., 2007; Langley et al., 2011) and 

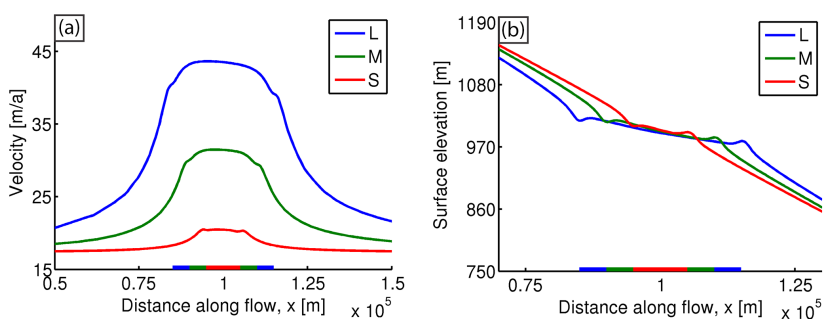

Figure 3. Surface velocity (a) and elevation (b) along flow $(n=3)$, through the center of the lake for various lake sizes. Velocity and surface profiles for the different lake sizes (L, M, S) are marked with different colors and the horizontal extent of each lake is marked with a horizontal bar at the bottom. Note the different horizontal scale for the two figures.

Lake Vostok (Studinger et al., 2003) as well as a small hump at the downstream end. Figure $3 \mathrm{~b}$ shows surface profiles for the three different lake sizes, each with the characteristic flattening of the surface as well as the dip and ridge features on each side of the lake.

Figure 4a shows a comparison of surface profiles for the $L_{M}$ lake size, made with a nonlinear viscosity $(n=3$ in Glen's flow law as used in our other experiments) versus a constant viscosity ( $\eta_{\text {const }}=10^{14} \mathrm{Pas}$ ) and a pressure- and temperature-dependent viscosity $(n=1)$ but otherwise using the same setup. The hummocky feature is noticeably absent from simulations with a constant viscosity. Figure $4 \mathrm{~b}$ and $\mathrm{c}$ show profiles of horizontal velocity and viscosity over the center of the lake for the three different viscosity cases. The horizontal velocity has been scaled with the horizontal velocity at the surface (the uppermost point of the vertical profile). For both the $n=1$ and $n=3$ cases, the horizontal velocity at depth is larger than at the surface.

A weaker contrast in basal traction inside and outside the lake, or a less pronounced switch in flow mode such as one might expect beneath an ice stream (Leysinger Vieli et al., 2007; Parrenin and Hindmarsh, 2007), decreases the amplitude of the dip and ridge features as can be witnessed in Fig. 5a, where surface profiles for simulations with different sliding coefficients and ice thickness are compared $(n=3)$. Isochrones relative to the ice base are shown in Fig. $5 \mathrm{~b}$ for two of the simulations presented in Fig. $4-n=3$ (blue line) and $\eta=10^{14}$ (red line) - in addition to isochrones for a simulation with a lower contrast in basal traction and a lower bed inclination than the other two (cyan line). The structure of internal layers depends heavily both on the contrast in basal traction and the viscosity formulation used. Low contrast results in small deflections of internal layers whereas a fixed viscosity (compared to flow with nonlinear viscosity and a similar surface velocity) results in larger deflections of internal layers due to the generally smaller ice flux at depth outside the lake compared to over it.

Lakes drain and fill on different timescales. Several studies have documented relatively rapid drainage events for sub-
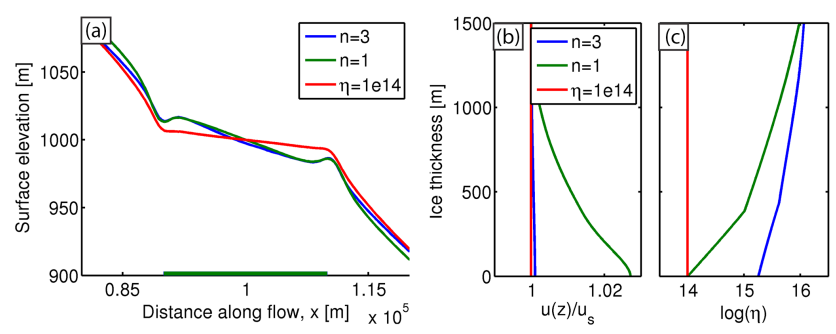

Figure 4. (a) Profiles of surface elevation in meters for the $L_{M}$ lake size and three different viscosity cases; fixed viscosity ( $\eta_{\text {const }}=10^{14} \mathrm{Pas}$, red), with flow exponent $n=1$ (green), and $n=3$ (blue) in Glen's flow law (Eq. 4). Vertical profiles of (b) the scaled horizontal velocity and (c) the logarithm of ice viscosity, over the center of the lake. The horizontal velocity has been scaled with the velocity magnitude at the surface.
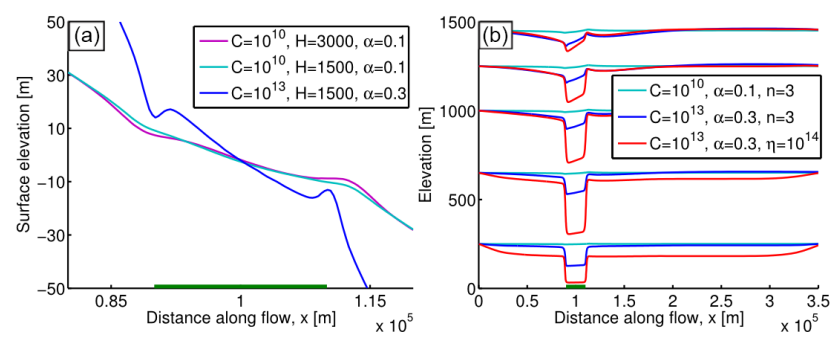

Figure 5. (a) Profiles of relative surface elevation in meters for the $L_{M}$ lake size for different values of the sliding coefficient and ice thickness. The blue line is the same surface profile as the blue line in Fig. 4a only displaced vertically for comparison. Note the different vertical scale compared to the previous figure. (b) Isochrone layers for the $n=3$ viscosity case with different values of the sliding coefficient (cyan and blue lines) and for the fixed viscosity case (red line). The lake size is $L_{M}$ and the isochrones are presented relative to the base.

glacial lakes in Antarctica (Gray et al., 2005; Wingham et al., 2006; Bell et al., 2007). Typically, drainage occurs over the course of several years but refilling takes much longer. To simulate such an event and what effect it could have on the internal structure of the ice, we set up a model run where the lake diameter shrinks during a 10-year period from the maximum $\left(L_{L}\right)$ to the smallest lake size used in the paper $\left(L_{S}\right)$. Figure 6 shows four different time slices of horizontal velocity, with black lines indicating isochrone layers. As the velocity field adjusts in time to the new BCs, a traveling wave is created at depth within the isochrone structure that transfers downstream with the flow of ice.

\section{Discussion}

The frictionless boundary levels the surface over the lake, changing surface gradients and causing the ice to speed up in the vicinity of the lake. The increase in velocity is further amplified by the effect of velocity gradients on ice viscosity. 

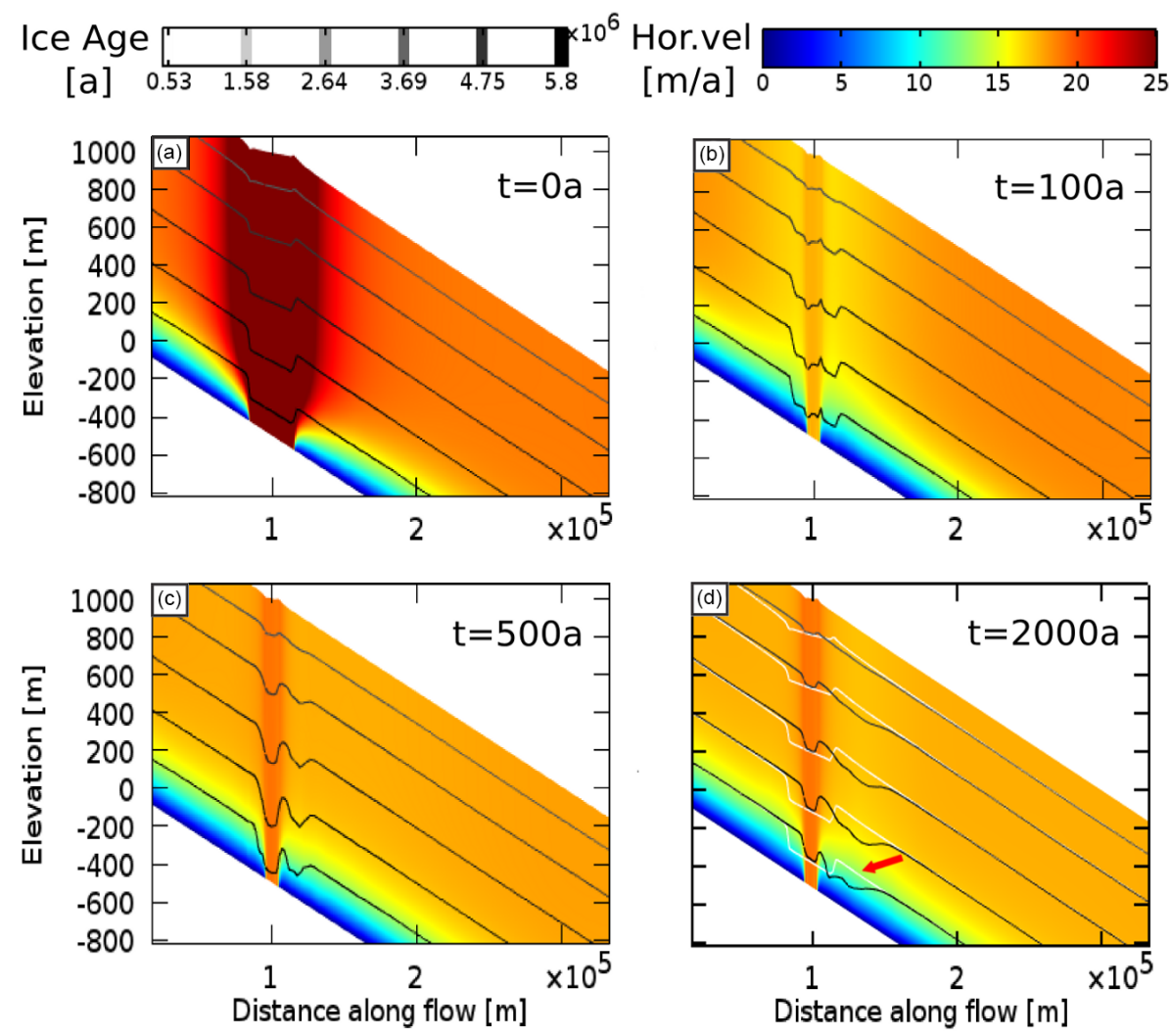

Figure 6. Four different time slices of the velocity and isochrone adjustment to a drainage event. The color scale represents horizontal velocity $\mathrm{m} \mathrm{a}^{-1}$ and gray to black lines indicate isochrones. (a) represents the initial stage $(t=0)$, (b) 100 years later $(t=100 \mathrm{a}),(\mathbf{c}) t=500 \mathrm{a}$, and (d) $t=2000 \mathrm{a}$. The white lines in the last time slice are the initial isochrone layers from $t=0$ and the red arrow points to the isochrone disturbance that advects downstream with the flow of ice.

Outside the lake, the velocity field is affected primarily by changes in surface gradients and longitudinal stresses and, to a lesser degree, by changes in ice viscosity and basal velocities. Over the lake, the ice moves more like an ice shelf, with almost uniform horizontal velocity throughout the ice column. The increase in velocity (Fig. 2a) is due to the lack of basal friction over the lake, causing the highest velocities to appear there, but secondary velocity peaks (Fig. 3) can also be discerned at the lake edges, which result from the interaction of surface evolution and ice dynamics. The velocity increase for the two fringe peaks propagates from the surface and downward whereas the velocity peak over the lake is mostly caused by acceleration in the basal layers of the ice sheet.

\subsection{Thermal regime}

For the given model setup, the geothermal flux is sufficient to ensure that the basal temperature reaches the pressuremelting point everywhere in the model. Internal deformation then adds to the available thermal energy with the potential to form a temperate layer with non-zero microscopic water content in the vicinity of the lake as seen in Fig. 2b, where a thin temperate layer has formed ( $\sim 70 \mathrm{~m}, 2$ vertical cells). Lakes in ice-streaming areas, where a considerable portion of the surface velocity arises due to sliding at the base, can be expected to have a much gentler transition in flow mode at the lake edges and much less deformational energy available. No temperate layer forms for simulations where the transition in sliding is considerably less sharp and more appropriate for streaming areas as in the cases with $C=10^{10}$ (Fig. 5).

The steeper temperature gradient over the lake efficiently leads away excess heat created by internal deformation at the upstream end, refreezing whatever microscopic water that was created upstream. Large quantities of microscopic water, in reality, would drain to the base ( $\gtrsim 3 \%$ ), although drainage is not included here as water content is relatively low. Two factors would contribute to facilitating freeze-on at the interface between ice and lake water, if it were included in the model. Firstly, draw-down of cold ice from above increases the temperature contrast in the lower part of the ice sheet; secondly, heat from internal deformation ceases with the removal of basal traction over the lake surface. Both result in a steepening of the temperature gradient close to the base, which removes heat more efficiently from the base and shifts the balance in favor of freeze-on. 
As lake size increases so too do horizontal velocities over the lake (Fig. 3), as well as the effective strain rates and the available deformational energy for internal heating. Accretion rates at the ice/lake interface would be limited by the amount of latent thermal energy that the ice above it can lead away efficiently, and any temperate layer formed by internal deformation at the lake boundary would, during its existence, block heat flow and thus accretion, until it completely refreezes.

\subsection{Transition zone}

The softening effect of local increases in effective stress at the lake edges effectively creates a vertical layer of soft ice in between higher viscosity ice (Fig. 2c). Strong vertical flow at the edges of the lake results from the localized lack of basal traction. A clear difference can be seen between simulations with constant viscosity and viscosity that depends on pressure and temperature (Fig. 4). The softening effect of increasing temperature and pressure with depth not only causes velocity changes in the vertical to be concentrated in the lower layers of an ice sheet but also means that for areas with varying basal traction, such as subglacial lakes, the ice at depth will support less lateral shear and lower longitudinal stresses compared to the upper layers where viscosity is higher and the ice stiffer. This in return means that as the ice encounters a slippery spot or a spot with a sharp decrease in basal traction, such as a subglacial lake, that the force balance will be different than in the isotropic case, where viscosity is constant. The imbalance in mass flux at depth must be compensated by a more localized increase in vertical flow and a subsequent drop in surface elevation at the upstream side and an upwelling at the downstream side of the lake due to the limited vertical extent of a typical ice sheet.

For large subglacial lakes, where the basal traction is 0 , the horizontal velocity at depth is predicted to be slightly larger (here about $0.1 \%$ for $n=3$, Fig. $4 \mathrm{~b}$ ) than at the surface. Lakes, such as Subglacial Lake Vostok, should therefore experience extrusion flow at the base, where the basal horizontal velocity exceeds that at the surface. Extrusion flow is not, however, a requirement for the formation of these dip and ridge features. To form them it is sufficient to have a sharp transition in sliding along with a negative downward gradient in ice viscosity. Our model further predicts that dips and ridges can form in situations where there is merely a strong decrease, not necessarily a complete disappearance, in basal traction.

\subsection{Drainage experiment}

Subglacial-lake drainage cycles (including both draining and filling) can have frequencies on decadal to centennial timescales or potentially even larger (Pattyn, 2008; Wingham et al., 2006). Although the drainage occurs over 10 years here, it can be seen as instantaneous given the generally slow flow of ice. The velocity field adjusts rather rapidly $(\sim 100$ a) to the new basal BCs relative to the time it takes for the isochrones to respond, as the flow of ice is relatively slow. For episodic drainage cycles, the strength of the response will depend partly on how long it takes for the lake to refill. After roughly 2000 years, the wave has moved far enough downstream to be more or less separated from its initial location (Fig. 6d). As both the upstream and downstream lake boundaries move during the drainage event, a two-troughed wave is created. In draining lakes where one end is much deeper than the other a single wave would be expected, as only the shallower end is likely to move significantly. The velocity of the moving boundary also affects the amplitude of the resulting isochrone disturbance (Wolovick et al., 2014), where a slip boundary, moving with the ice, is capable of distorting isochrone layers to a much greater extent than stationary slip boundaries. For maximum effect, the boundary should be moving at a velocity comparable to the averaged ice column velocity. Only slip boundaries moving with the ice are capable of distorting layers to a greater extent than stationary boundaries. Boundaries moving in opposite directions to ice flow, like our downstream lake boundary, will have a smaller impact on internal layers than a stationary boundary as the relative horizontal velocity increases.

Water in very active subglacial systems, such as recently discovered in West Antarctica (Gray et al., 2005; Fricker et al., 2007), has relatively short residence times and fast circulation, contrary to previous beliefs. The impact of such short drainage cycles, where both drainage and refilling happen on decadal timescales, is unlikely to have a strong effect on the internal isochrone layers as it takes a long time for the ice to respond. Regular drainage events in subglacial lakes that have a much shorter cycle than the time it takes for a particle of ice to be brought up by vertical flow at the edge of the lake will therefore probably not be easily detectable in the isochrone structure. If the frequency of drainage cycles is high, the ice will have little time to respond and the amplitude of the resulting wave will be small. In contrast, drainage of large lakes in areas with low basal melt rates and consequently long filling times could be expected to generate traveling waves, downstream of the lake, with a sufficiently large amplitude to be detectable within downstream isochrones. The amplitude of the traveling wave would be expected to be similar in magnitude as the steady-state isochrone disturbance over the lake itself (Fig. 6). In our simulated scenario of Fig. 6 the traveling-wave amplitudes of $\sim 100 \mathrm{~m}$ would be well within the bounds of detectability with modern radar systems. Drainage of subglacial lakes where the transition in flow mode is less abrupt would result in smaller amplitudes (Fig. 5b). As layer stratigraphy is often quite complex, a numerical model of ice age and velocities would be needed to separate the effect of temporally changing lake size, or basal conditions, from layer deflections caused by varying basal topography or rheology. 
For our particular setup, the isochrone disturbance, or the traveling wave, should eventually overturn and create a fold as the stress situation downstream of the lake is essentially one of simple shear without any longitudinal extension (Waddington et al., 2001; Jacobson and Waddington, 2005). Resolving this in the model would require an equally fine resolution downstream of the lake, as over the lake itself, which is not done here. For a subglacial lake situated at the onset of streaming flow, a fold might not be expected though, as overturning would be counteracted by longitudinal extension and vertical compression, which would tend to flatten all layer disturbances. In general, both horizontal shear and longitudinal extension can be assumed to be present and, thus, whether a layer disturbance develops into a fold or flattens out, eventually to disappear, will be decided by the balance between the two (Waddington et al., 2001).

\section{Conclusions}

Subglacial lakes represent areas of the ice-sheet base which are incapable of exerting any horizontal stress on the overlying ice. A rapid transition between little to full sliding at the lake edges causes intense deformation and internal heating, leading both to an increase in enthalpy and strain softening of ice. The decrease in viscosity with depth leads to preferential deformation of the lower layers of an ice sheet which, along with a sharp transition in sliding, results in a hummocky surface feature above the upstream and downstream edges of subglacial lakes. These dip and ridge features can be taken as evidence for a rapid transition in basal sliding, with strong vertical movement of ice as a result. Lakes without this feature would be expected to experience a more gradual increase in sliding approaching the lake, a lower contrast in basal traction or continued fast flow downstream, as with subglacial lakes at the onset of or in ice-streaming areas. Over the lake itself, the ice moves more like an ice shelf, with zero basal traction and virtually no internal strain heating. As a result, temperature gradients over the lake steepen, making them more prone to freeze-on at the ice/water interface. A rapid decrease in lake size (or basal friction) causes a traveling wave to be created at depth within isochrone layers, suggesting that certain aspects of lake history are preserved within them and could potentially be deciphered from radio echo sounding data downstream of lake locations when combined with output from numerical models.

Acknowledgements. Funding for this work came from the Research Council of Norway (RCN), Statoil, Det Norske ASA and BG group, Norway (grant 200672), to the PetroMaks project "Glaciations in the Barents Sea area (GlaciBar)", and from the Research School in Arctic Marine Geology and Geophysics (AMGG) at the University of Troms $\varnothing$. This is also a contribution to the Centre of Excellence: Arctic Gas Hydrate, Environment and Climate (CAGE) funded by RCN (grant 223259). In addition, we would like to thank Nina Wilkens and Martin Rückamp for help with getting started with COMSOL, the Stallo support team for invaluable assistance, and Gwendolyn Leysinger Vieli, as well as one anonymous reviewer and the editor Robert Bingham for constructive reviews and comments that greatly improved the quality of the manuscript.

Edited by: R. Bingham

\section{References}

Aschwanden, A., Bueler, E., Khroulev, C., and Blatter, H.: An enthalpy formulation for glaciers and ice sheets, J. Glaciol., 58, 441-457, 2012.

Bell, R., Studinger, M., Shuman, C., Fahnestock, M., and Joughin, I.: Large subglacial lakes in East Antarctica at the onset of fast-flowing ice streams, Nature, 445, 904-907, 2007.

Bentley, M., Christoffersen, P., Hodgson, D., Smith, A., Tulaczyk, S., and Le Brocq, A.: Subglacial lake sediments and sedimentary processes: potential archives of ice sheet evolution, past environmental cange, and the presence of life, in: Antarctic Subglacial Aquatic Environments, American Geophysical Union, Washington, D.C., 83-110, doi:10.1029/GM192, 2013.

Christoffersen, P., Tulaczyk, S., Wattrus, N., Peterson, J., QuintanaKrupinski, N., Clark, C., and Sjunneskog, C.: Large subglacial lake beneath the Laurentide Ice Sheet inferred from sedimentary sequences, Geology, 36, 563-566, 2008.

Dowdeswell, J. and Siegert, M.: The dimensions and topographic setting of Antarctic subglacial lakes and implications for largescale water storage beneath continental ice sheets, Geol. Soc. Am. Bull., 111, 254-263, 1999.

Duval, P.: The role of the water content on the creep rate of polycrystalline ice, in: Isotopes and Impurities in Snow and Ice, IAHS Publication, Wallingford, 118, 29-33, 1977.

Fricker, H., Scambos, T., Bindschadler, R., and Padman, L.: An active subglacial water system in West Antarctica mapped from space, Science, 315, 1544-1548, 2007.

Glen, J.: The creep of polycrystalline ice, P. Roy. Soc. Lond. A, 228, 519-538, 1955.

Gray, L., Joughin, I., Tulaczyk, S., Spikes, V., Bindschadler, R., and Jezek, K.: Evidence for subglacial water transport in the West Antarctic Ice Sheet through three-dimensional satellite radar interferometry, Geophys. Res. Lett., 32, L03501, doi:10.1029/2004GL021387, 2005.

Greve, R.: Application of a polythermal three-dimensional ice sheet model to the Greenland ice sheet: response to steady-state and transient climate scenarios, J. Climate, 10, 901-918, 1997.

Greve, R. and Blatter, H.: Dynamics of Ice Sheets and Glaciers, Springer Science \& Business Media, Springer-Verlag, Berlin, Heidelberg, 49-72, 2009.

Hindmarsh, R.: The role of membrane-like stresses in determining the stability and sensitivity of the Antarctic ice sheets: back pressure and grounding line motion, Philos. T. Roy. Soc. Lond. A, 364, 1733-1767, 2006.

Hindmarsh, R., Leysinger Vieli, G., Raymond, M., and Gudmundsson, G.: Draping or overriding: the effect of horizontal stress gradients on internal layer architecture in ice sheets, J. Geophys. Res.-Earth, 111, F02018, doi:10.1029/2005JF000309, 2006. 
Hindmarsh, R., Leysinger Vieli, G., and Parrenin, F.: A largescale numerical model for computing isochrone geometry, Ann. Glaciol., 50, 130-140, 2009.

Hutter, K.: A mathematical model of polythermal glaciers and ice sheets, Geophys. Astro. Fluid, 21, 201-224, 1982.

Jacobson, H. and Waddington, E.: Recumbent folding of divide arches in response to unsteady ice-divide migration, J. Glaciol., 51, 201-209, 2005.

Kamb, B. and Echelmeyer, K.: Stress-gradient coupling in glacier flow: I. Longitudinal averaging of the influence of ice thickness and surface slope, J. Glaciol., 32, 267-284, 1986.

Kleiner, T., Rückamp, M., Bondzio, J. H., and Humbert, A.: Enthalpy benchmark experiments for numerical ice sheet models, The Cryosphere, 9, 217-228, doi:10.5194/tc-9-217-2015, 2015.

Langley, K., Kohler, J., Matsuoka, K., Sinisalo, A., Scambos, T., Neumann, T., Muto, A., Winther, J., and Albert, M.: Recovery Lakes, East Antarctica: radar assessment of sub-glacial water extent, Geophys. Res. Lett., 38, L05501, doi:10.1029/2010GL046094, 2011.

Langley, K., Tinto, K., Block, A., Bell, R., Kohler, J., and Scambos, T.: Onset of fast ice flow in Recovery Ice Stream, East Antarctica: a comparison of potential causes, J. Glaciol., 60, 1007-1014, 2014.

Leysinger Vieli, G., Hindmarsh, R., and Siegert, M.: Threedimensional flow influences on radar layer stratigraphy, Ann. Glaciol., 46, 22-28, 2007.

Palmer, S., Dowdeswell, J., Christoffersen, P., Young, D., Blankenship, D., Greenbaum, J., Benham, T., Bamber, J., and Siegert, M.: Greenland subglacial lakes detected by radar, Geophys. Res. Lett., 40, 6154-6159, doi:10.1002/2013GL058383, 2013.

Parrenin, F. and Hindmarsh, R.: Influence of a non-uniform velocity field on isochrone geometry along a steady flowline of an ice sheet, J. Glaciol., 53, 612-622, 2007.

Parrenin, F., Hindmarsh, R., and Rémy, F.: Analytical solutions for the effect of topography, accumulation rate and lateral flow divergence on isochrone layer geometry, J. Glaciol., 52, 191-202, 2006.

Pattyn, F.: Investigating the stability of subglacial lakes with a full Stokes ice-sheet model, J. Glaciol., 54, 353-361, 2008.

Pattyn, F., De Smedt, B., and Souchez, R.: Influence of subglacial Vostok lake on the regional ice dynamics of the Antarctic ice sheet: a model study, J. Glaciol., 50, 583-589, 2004.

Sergienko, O., MacAyeal, D., and Bindschadler, R.: Causes of sudden, short-term changes in ice-stream surface elevation, Geophys. Res. Lett., 34, L22503, doi:10.1029/2007GL031775, 2007.
Siegert, M.: Antarctic subglacial lakes, Earth-Sci. Rev., 50, 29-50, 2000.

Siegert, M. and Kwok, R.: Ice-sheet radar layering and the development of preferred crystal orientation fabrics between Lake Vostok and Ridge B, central East Antarctica, Earth Planet. Sc. Lett., 179, 227-235, 2000.

Siegert, M., Dowdeswell, J., Gorman, M., and McIntyre, N.: An inventory of Antarctic sub-glacial lakes, Antarct. Sci., 8, 281286, 1996.

Siegert, M., Le Brocq, A., and Payne, A.: Hydrological connections between Antarctic subglacial lakes, the flow of water beneath the East Antarctic Ice Sheet and implications for sedimentary processes, in: Glacial Sedimentary Processes and Products, Blackwell Publishing Ltd., Oxford, UK, 3-10, 2007.

Stearns, L., Smith, B., and Hamilton, G.: Increased flow speed on a large East Antarctic outlet glacier caused by subglacial floods, Nat. Geosci., 1, 827-831, 2008.

Steinemann, S.: Results of preliminary experiments on the plasticity of ice crystals, J. Glaciol., 2, 404-412, 1954.

Studinger, M., Bell, R. E., Karner, G. D., Tikku, A. A., Holt, J. W., Morse, D. L., Richter, T. G., Kempf, S. D., Peters, M. E., Blankenship, D. D., Sweeney, R. E., and Rystrom, V. L.: Ice cover, landscape setting, and geological framework of Lake Vostok, East Antarctica, Earth Planet. Sc. Lett., 205, 195-210, 2003.

Thoma, M., Grosfeld, K., Mayer, C., and Pattyn, F.: Interaction between ice sheet dynamics and subglacial lake circulation: a coupled modelling approach, The Cryosphere, 4, 1-12, doi:10.5194/tc-4-1-2010, 2010.

Waddington, E., Bolzan, J., and Alley, R.: Potential for stratigraphic folding near ice-sheet centers, J. Glaciol., 47, 639-648, 2001.

Weertman, J.: Sliding-no sliding zone effect and age determination of ice cores, Quaternary Res., 6, 203-207, 1976.

Wingham, D., Siegert, M., Shepherd, A., and Muir, A.: Rapid discharge connects Antarctic subglacial lakes, Nature, 440, 1033 1036, 2006.

Wolovick, M., Creyts, T., Buck, W., and Bell, R.: Traveling slippery patches produce thickness-scale folds in ice sheets, Geophys. Res. Lett., 41, 8895-8901, doi:10.1002/2014GL062248, 2014.

Wright, A. and Siegert, M.: A fourth inventory of Antarctic subglacial lakes, Antarct. Sci., 24, 659-664, 2012. 